\title{
AGE, GROWTH AND MATURATION OF SWORDTIP SQUID (PHOTOLOLIGO EDULIS) IN THE SOUTHERN EAST CHINA SEA
}

\author{
Kae-Yih Wang \\ Department of Environment Biology and Fisheries Science, National Taiwan Ocean University, Keelung 20224, Taiwan, \\ R.O.C \\ Kuo-Tien Lee \\ Department of Environment Biology and Fisheries Science, National Taiwan Ocean University, Keelung 20224, Taiwan, \\ R.O.C \\ Cheng-Hsin Liao \\ Department of Environment Biology and Fisheries Science, National Taiwan Ocean University, Keelung 20224, Taiwan, \\ R.O.C, chliao@mail.ntou.edu.tw
}

Follow this and additional works at: https://jmstt.ntou.edu.tw/journal

Part of the Aquaculture and Fisheries Commons

\section{Recommended Citation}

Wang, Kae-Yih; Lee, Kuo-Tien; and Liao, Cheng-Hsin (2010) "AGE, GROWTH AND MATURATION OF SWORDTIP SQUID (PHOTOLOLIGO EDULIS) IN THE SOUTHERN EAST CHINA SEA," Journal of Marine Science and Technology. Vol. 18: Iss. 1, Article 12.

DOI: $10.51400 / 2709-6998.1870$

Available at: https://jmstt.ntou.edu.tw/journal/vol18/iss1/12

This Research Article is brought to you for free and open access by Journal of Marine Science and Technology. It has been accepted for inclusion in Journal of Marine Science and Technology by an authorized editor of Journal of Marine Science and Technology. 


\section{AGE, GROWTH AND MATURATION OF SWORDTIP SQUID (PHOTOLOLIGO EDULIS) IN THE SOUTHERN EAST CHINA SEA}

\section{Acknowledgements}

We would like to express our appreciation to the people who provided their help during this study. We also extend our appreciation to Dr. Chang-tai Shih, Visiting Professor of National Taiwan Ocean University from the Canadian Museum of Nature, for his critical review and comments on the manuscript. This study was financially supported by a grant (NSC 95-2313-B-019-017) from the National Science Council of Republic of China and another grant (95AS-14.1.1-FA-F3) from the Fisheries Agency, Council of Agriculture, Taiwan, R.O.C 


\title{
AGE, GROWTH AND MATURATION OF SWORDTIP SQUID (PHOTOLOLIGO EDULIS) IN THE SOUTHERN EAST CHINA SEA
}

\author{
Kae-Yih Wang*, Kuo-Tien Lee*, and Cheng-Hsin Liao*
}

Key words: Photololigo edulis, age, growth, maturation, East China Sea.

\section{ABSTRACT}

The reproductive biology, and age and growth of the swordtip squid (Photololigo edulis) in the East China Sea were examined based on the growth ring of statoliths from 1797 specimens during the period of November 2002 to November 2004. The maximum age observed was 261 days in female and 253 days in male, an evidence showing that swordtip squid has a longevity of about 9 months in both sexes. Growth in mantle length (ML) and body weight (BW) in both sexes was best described by the exponential model. There was significantly difference in somatic or statolith growth between the sexes. However, absolute daily growth rates (DGRs) and instantaneous relative growth rate $(\mathrm{G})$ for $\mathrm{ML}$ and $\mathrm{BW}$ were similar for both sexes until 200-220 days, after which they became higher for males. In our samples, the youngest mature squid was 139 days in female and 102 days in male. Females matured about two months later in age than males in average. The hatching season was throughout the year but with several peaks, namely, October-November in 2002, March-April and November in 2003, March in 2004. Therefore, we suggested that swordtip squid has two main spawning seasons, spring (March-April) and autumn (October-November).

\section{INTRODUCTION}

The swordtip squid (Photololigo edulis) is a large-sized loliginid squid, distributed widely in the western Pacific. It usually appears over the continental shelf of northern Australia, Philippine Islands, northern South China Sea, and central Japan [5]. It is commercially important to the trawl and torchlight fisheries in the East China Sea. Annual catch of the swordtip squid was about 10,000 metric tons (mt) according to

Paper submitted 05/29/08; revised 02/25/09; accepted 03/04/09. Author for correspondence: Cheng-Hsin Liao (e-mail: chliao@mail.ntou.edu.tw).

*Department of Environment Biology and Fisheries Science, National Taiwan Ocean University, Keelung 20224, Taiwan, R.O.C.
Japan and China fishing data $[11,14]$. The swordtip squid has been fished since late 1950s in Taiwan (Fishery Yearbook), where its main fishing grounds are in the southern East China Sea [10]. Annual catches in the southern East China Sea were below 6,000 $\mathrm{mt}$ from late 1950 s to 1993 , but reached 8,000$21,000 \mathrm{mt}$ since 1994. The recent increase in catches is probably due to the modernized fishing vessels that improve fishing ground exploitation. The rapid development of this fishery encourages the need to study the biological parameters (age, growth, maturity, etc.) and the temporal-spatial variations of the abundance of this important resource.

Some stock assessment studies have been conducted on the swordtip squid to develop effective management measures [10]. Reproductive biology studies by Wang et al. [21] and Wang [22] indicated the species may spawn all year round. Natsukari et al. [17] analyzed the age and growth based on the statoliths of 773 swordtip squid collected from the southwestern coast of the Sea of Japan (temperate waters). They showed that the longevity of swordtip squid may be less than one year, and the growth rates vary considerably among individuals. However, the age, growth, and spawning season for the swordtip squid in the southern East China Sea (subtropical waters) are poorly known.

The aim of this study is to understand the age, growth and spawning season of the swordtip squid in the southern East China Sea based on analysis of the statolith growth increment which has already been applied to growth studies in many squid species [23]. We then speculated that growth of the swordtip squid in subtropical waters might be different from that in temperate waters due to the difference in habitat temperature, we also compared the present results with those of the previous study on age and growth for the swordtip squid by Natsukari et al. [17].

\section{MATERIALS AND METHODS}

Samples of the swordtip squid were taken from the commercial torch-light fishery in the southern East China Sea during the period of November 2002 to November 2004. The main fishing activity was on the shallow water with the isobaths of 100 to $200 \mathrm{~m}$ in the area between $25^{\circ} \mathrm{N}$ and $29^{\circ} \mathrm{N}$ and $121^{\circ} \mathrm{E}$ and $126^{\circ} \mathrm{E}$ (Fig. 1). Monthly samples, each of over 200 


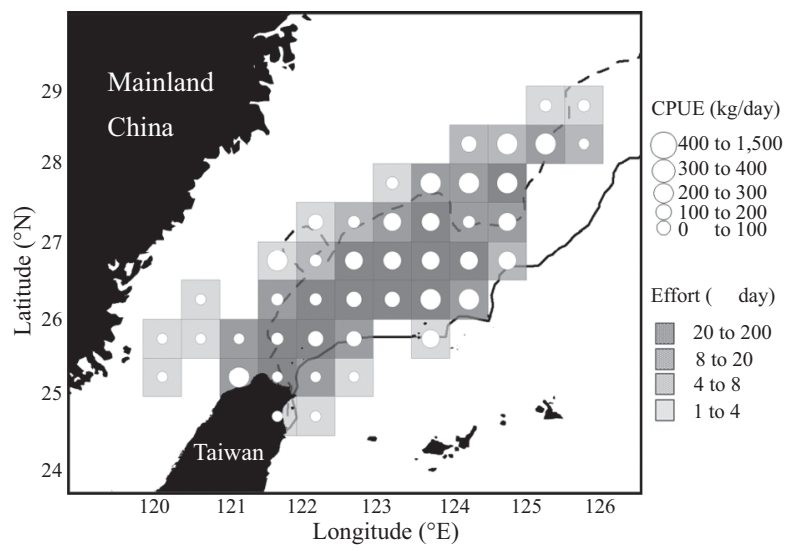

Fig. 1. The torch-light fishery activities in the southern East China Sea during the period of November, 2002 to November, 2004. The dashed and solid lines are the $100 \mathrm{~m}$ and $200 \mathrm{~m}$ bottom contours, respectively.

squids, were frozen on board immediately after collection and returned to the laboratory in Taiwan for further analysis. In order to increase the number of samples and the size-age range from large squid to pre-recruits, additional samples from the jig fisheries and the scientific survey carried out by research vessel in the same area between May 2003 and October 2004 were also used.

In measuring squid, we followed Pierce et al. [19] to set the accuracy at $0.05 \mathrm{~mm}$ for dorsal mantle length (ML) and 0.01 $\mathrm{g}$ for total body mass (BW), gonad weight $(\mathrm{GW})$, stomach content weight (SW), and the gonadosomatic indices (GSI). Maturity stages were recorded (I: immature; II-III: maturing; IV: mature) according to Macy [12].

A sub-sample of statoliths was collected from each sample of squid for age analysis. A monthly sample of 60-80 individuals was selected and processed during the study period (Table 1). Before grinding, total statolith length (TSL) was measured from the anterior side to the nearest $0.01 \mathrm{~mm}$. The focus-rostral length (FRL) of ground statoliths was also measured to the nearest $0.01 \mathrm{~mm}$. We followed Natsukari et al. [17] to grind the statoliths and count the growth increments. The statoliths were embedded concave side down in epoxy resin on a glass slide and ground with fine waterproof sandpaper (\#800-1500) and polished with alumina powder $(0.3 \mu \mathrm{m})$ from the anterior side. The number of growth increments was counted from the focus to the edge of the rostrum, using a microscope (Olympus BX-51) under 400× magnification. Usually the right statolith was read. The left statolith was used only when reading of the right one became impossible. Following Natsukari et al. [17], we assumed growth increments of statoliths were deposited daily as in other loliginids [8]. Individual hatching dates were back tracked from day of capture.

Growth curves were constructed using the noniterative least-squares method (SAS 9.0). Several curves were fitted to age-ML or BW data: linear, power, exponential, von Berta- lanffy, logistic, and Gompertz. The best-fit model was determined by the highest goodness of fit, the examination of residuals for any systematic pattern, and the reliability of the parameter estimates. Analysis of covariance (ANCOVA) was used to determine the significance of the differences between slopes and intercepts of the calculated equations and for testing the allometry of growth (age-ML, age-BW etc.).

We estimated absolute daily growth rates (DGRs, mm or $\mathrm{g} /$ day) and instantaneous relative growth rate $(\mathrm{G})$ to describe the growth of squid. DGR and G were calculated for each 20-day interval by sex [3]:

$$
\mathrm{DGR}=\frac{S_{2}-S_{1}}{T}, \mathrm{G}=\frac{\ln S_{2}-\ln S_{1}}{T}
$$

Where $S_{2}$ and $S_{1}$ are the calculated dimensions (ML, in $\mathrm{mm}$ or $\mathrm{BW}$, in $\mathrm{g}$ ) at the beginning and the end of each interval of time $(T=20$ days).

\section{RESULTS}

\section{Age Composition}

The ML of aged individuals ranged from 22 to $405 \mathrm{~mm} \mathrm{(22}$ to $84 \mathrm{~mm}$ for unsex, 46 to $306 \mathrm{~mm}$ for females, and 47 to 405 for males) and the BW of aged individuals ranged from 1 to $818 \mathrm{~g}$ ( 1 to $23 \mathrm{~g}$ for unsex, 5 to $449 \mathrm{~g}$ for females, and 5 to 818 $\mathrm{g}$ for males) (Table 1). The youngest squid was 41 days old. Sex could be identified in specimens from 56 days old. The maximum age was observed 261 days in female and 253 days in male.

\section{Statolith Growth}

TSL and FRL were measured from 1912 and 1797 specimens, respectively. The smallest TSL $(0.7 \mathrm{~mm})$ was observed in juvenile $(21.9 \mathrm{~mm} \mathrm{ML})$, and the largest $(2.06 \mathrm{~mm})$ in a mature female (308.8 $\mathrm{mm} \mathrm{ML).} \mathrm{The} \mathrm{largest} \mathrm{male} \mathrm{TSL} \mathrm{(2.0}$ $\mathrm{mm})$ was recorded from a mature male of $303.7 \mathrm{~mm}$ ML. TSL-ML and FRL-ML relationship was best described by a power model (Fig. 2). There were significant differences for TSL-ML and FRL-BW relationships between sexes (Table 2).

Statolith size at age relationships was best described by the linear model (Fig. 3). Comparison of models in different sexes shows significant differences for age-TSL relationship, and for age-FRL relationship (Table 2).

\section{Age and Gowth of Swordtip Squid}

The minimum age (56 days) was observed in female squid of $49 \mathrm{~mm}$ ML and $6 \mathrm{~g} \mathrm{BW}$. The maximum age was 261 days in a mature female (274 mm ML, $409 \mathrm{~g} \mathrm{BW}$ ) and 253 days in a mature male of (345 mm ML, $438 \mathrm{~g} \mathrm{BW}$ ), respectively. The largest specimen (mature male, $405 \mathrm{~mm} \mathrm{ML}$ and $818 \mathrm{~g} \mathrm{BW}$ ) has 200 growth increments on its statoliths. After reaching the sexual maturity, the swordtip squid seems to grow continuously. 
Table 1. Mantle length (ML) and body weight (BW) of the swordtip squid collected from the southern East China Sea between November 2002 and November 2004.

\begin{tabular}{|c|c|c|c|c|c|c|c|c|c|c|c|c|c|c|c|c|c|c|c|c|c|}
\hline \multirow{3}{*}{ Year } & \multirow{3}{*}{ Month } & \multicolumn{6}{|c|}{ Male } & \multicolumn{7}{|c|}{ Female } & \multicolumn{7}{|c|}{ Unsex } \\
\hline & & \multirow{2}{*}{$\mathrm{n}$} & age(day) & \multicolumn{2}{|c|}{$\mathrm{ML}(\mathrm{mm})$} & \multicolumn{2}{|c|}{$\mathrm{BW}(\mathrm{g})$} & \multirow{2}{*}{$\mathrm{n}$} & \multicolumn{2}{|c|}{ age(day) } & \multicolumn{2}{|c|}{$\mathrm{ML}(\mathrm{mm})$} & \multicolumn{2}{|c|}{$\mathrm{BW}(\mathrm{g})$} & & \multicolumn{2}{|c|}{ age(day) } & \multicolumn{2}{|c|}{$\mathrm{ML}(\mathrm{mm})$} & \multicolumn{2}{|c|}{$\mathrm{BW}(\mathrm{g})$} \\
\hline & & & $\max \min$ & $\max$ & $\min$ & $\max$ & $\min$ & & $\max$ & $\min$ & $\max$ & $\min$ & $\max$ & $\min$ & & $\max$ & $\min$ & $\max$ & $\min$ & $\max$ & $\min$ \\
\hline \multirow[t]{2}{*}{2002} & Nov. & 39 & 224142 & 150 & 77 & 108 & 20 & 22 & 219 & 133 & 154 & 90 & 123 & 35 & & & & & & & \\
\hline & Dec. & 40 & 230105 & 140 & 70 & 119 & 16 & 18 & 187 & 115 & 131 & 63 & 65 & 13 & 3 & 119 & 68 & 48 & 30 & 8 & 2 \\
\hline \multirow[t]{11}{*}{2003} & Jan. & 32 & $158 \quad 97$ & 103 & 52 & 49 & 8 & 34 & 179 & 85 & 104 & 51 & 55 & 8 & 1 & 113 & 113 & 46 & 46 & 7 & 7 \\
\hline & Feb. & 34 & 173100 & 103 & 47 & 47 & 6 & 31 & 149 & 82 & 99 & 46 & 41 & 5 & 3 & 115 & 77 & 47 & 44 & 6 & 5 \\
\hline & Mar. & 35 & 169102 & 157 & 50 & 133 & 7 & 31 & 219 & 114 & 156 & 52 & 144 & 8 & & & & & & & \\
\hline & Apr. & 35 & 174107 & 114 & 48 & 60 & 7 & 19 & 178 & 115 & 87 & 50 & 30 & 8 & 1 & 103 & 103 & 44 & 44 & 7 & 7 \\
\hline & May & 29 & 16799 & 107 & 52 & 51 & 10 & 41 & 168 & 92 & 96 & 60 & 37 & 11 & & & & & & & \\
\hline & Jun. & 43 & 209102 & 194 & 57 & 164 & 9 & 25 & 220 & 121 & 233 & 75 & 331 & 19 & & & & & & & \\
\hline & Jul. & 30 & 148101 & 85 & 52 & 25 & 8 & 32 & 154 & 100 & 81 & 50 & 24 & 7 & 3 & 131 & 96 & 53 & 50 & 8 & 7 \\
\hline & Aug. & 50 & 188116 & 145 & 66 & 98 & 13 & 24 & 159 & 119 & 109 & 73 & 48 & 19 & & & & & & & \\
\hline & Sep. & 38 & 192117 & 154 & 61 & 118 & 13 & 39 & 186 & 135 & 133 & 54 & 90 & 9 & & & & & & & \\
\hline & Oct. & 38 & $208 \quad 145$ & 144 & 70 & 107 & 20 & 23 & 203 & 129 & 114 & 78 & 64 & 22 & & & & & & & \\
\hline & Nov. & 17 & $134 \quad 71$ & 105 & 68 & 36 & 13 & 31 & 133 & 56 & 115 & 49 & 53 & 6 & 12 & 83 & 66 & 84 & 45 & 23 & 4 \\
\hline \multirow[t]{10}{*}{2004} & Feb. & 34 & 16396 & 83 & 49 & 26 & 6 & 26 & 146 & 112 & 92 & 50 & 34 & 7 & & & & & & & \\
\hline & Mar. & 46 & $171 \quad 114$ & 119 & 48 & 62 & 5 & 26 & 158 & 111 & 93 & 50 & 30 & 6 & 2 & 158 & 121 & 47 & 47 & 6 & 5 \\
\hline & Apr. & 45 & $177 \quad 101$ & 108 & 49 & 52 & 5 & 27 & 168 & 124 & 89 & 48 & 29 & 7 & 2 & 139 & 133 & 45 & 41 & 5 & 4 \\
\hline & May & 47 & 176111 & 146 & 61 & 95 & 12 & 30 & 192 & 129 & 181 & 71 & 169 & 16 & & & & & & & \\
\hline & Jun. & 44 & 154115 & 115 & 65 & 58 & 14 & 22 & 169 & 125 & 100 & 70 & 43 & 16 & & & & & & & \\
\hline & Jul. & 40 & $177 \quad 125$ & 181 & 65 & 163 & 13 & 35 & 198 & 120 & 167 & 71 & 152 & 17 & & & & & & & \\
\hline & Aug. & 29 & 196124 & 140 & 69 & 95 & 17 & 43 & 192 & 130 & 217 & 67 & 256 & 16 & & & & & & & \\
\hline & Sep. & 39 & 192119 & 107 & 55 & 57 & 10 & 27 & 195 & 118 & 101 & 48 & 61 & 8 & 3 & 174 & 119 & 62 & 55 & 18 & 11 \\
\hline & Oct. & 45 & 223102 & 169 & 76 & 140 & 21 & 20 & 216 & 86 & 150 & 91 & 114 & 34 & & & & & & & \\
\hline & Nov. & 18 & 232161 & 176 & 103 & 168 & 53 & 33 & 253 & 131 & 199 & 102 & 246 & 49 & & & & & & & \\
\hline \multirow[t]{2}{*}{ addition } & Large & 96 & 253154 & 405 & 154 & 818 & 114 & 121 & 261 & 186 & 306 & 77 & 449 & 26 & & & & & & & \\
\hline & small & & & & & & & & & & & & & & 44 & 84 & 41 & 47 & 22 & 3 & 1 \\
\hline total & & 943 & & & & & & 780 & & & & & & & 74 & & & & & & \\
\hline
\end{tabular}

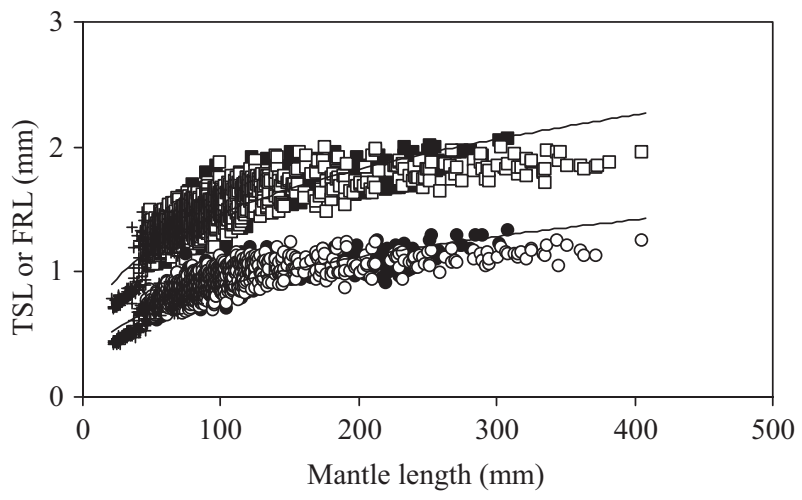

Fig. 2. Relationship between ML and TSL (squares) and FRL (circles), and their power curves of the swordtip squid of the southern East China Sea. Females in black and males in white.

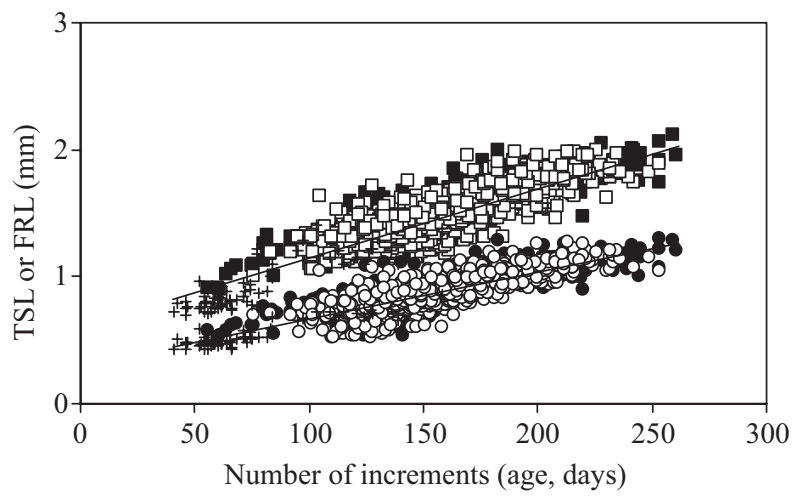

Fig. 3. Relationship between age and TSL (squares) and FRL (circles), and their linear model of the swordtip squid of the southern East China Sea. Females in black and males in white. 
Table 2. Parameter estimation of the growth models for females, males, and both sexes.

\begin{tabular}{|c|c|c|c|c|c|}
\hline & Sex & $\mathrm{n}$ & Model & $\mathrm{r}^{2}$ & Testing between sexes differences \\
\hline \multicolumn{6}{|l|}{ TSL vs. ML } \\
\hline & All-combined & 1912 & $\mathrm{y}=0.36 \mathrm{ML}^{0.307}$ & 0.73 & \\
\hline & Females & 815 & $\mathrm{y}=0.42 \mathrm{ML}^{0.274}$ & 0.72 & $\mathrm{~F}_{\text {equal slopes }}=9.79, \mathrm{P}=0.002^{*}$ \\
\hline & Males & 1014 & $\mathrm{y}=0.47 \mathrm{ML}^{0.249}$ & 0.67 & $\mathrm{~F}_{\text {equal intercepts }}=0.85, \mathrm{P}=0.356$ \\
\hline \multicolumn{6}{|l|}{ FRL vs. ML } \\
\hline & All-combined & 1874 & $\mathrm{y}=0.20 \mathrm{ML}^{0.332}$ & 0.72 & \\
\hline & Females & 807 & $\mathrm{y}=0.24 \mathrm{ML}^{0.293}$ & 0.67 & $\mathrm{~F}_{\text {equal slopes }}=3.95, \mathrm{P}=0.042^{*}$ \\
\hline & Males & 978 & $\mathrm{y}=0.25 \mathrm{ML}^{0.276}$ & 0.65 & $\mathrm{~F}_{\text {equal intercepts }}=0.42, \mathrm{P}=0.516$ \\
\hline \multicolumn{6}{|l|}{ TSL vs. Age } \\
\hline & All-combined & 1797 & $\mathrm{y}=0.0054 \mathrm{Age}+0.62$ & 0.76 & \\
\hline & Females & 780 & $\mathrm{y}=0.0051 \mathrm{Age}+0.69$ & 0.75 & $\mathrm{~F}_{\text {equal slopes }}=0.06, \mathrm{P}=0.805$ \\
\hline & Males & 943 & $y=0.0051$ Age +0.66 & 0.68 & $\mathrm{~F}_{\text {equal intercepts }}=9.12, \mathrm{P}=0.003^{*}$ \\
\hline \multicolumn{6}{|l|}{ FRL vs. Age } \\
\hline & All-combined & 1797 & $\mathrm{y}=0.0037 \mathrm{Age}+0.31$ & 0.74 & \\
\hline & Females & 780 & $y=0.0037$ Age +0.31 & 0.74 & $\mathrm{~F}_{\text {equal slopes }}=1.95, \mathrm{P}=0.162$ \\
\hline & Males & 943 & $\mathrm{y}=0.0037 \mathrm{Age}+0.30$ & 0.67 & $\mathrm{~F}_{\text {equal intercepts }}=2.14, \mathrm{P}=0.033^{*}$ \\
\hline
\end{tabular}

n: number of specimens, TSL: total statolith length, FRL: focus-rostral lengthl length.

*Significant at $P<0.05$.

Table 3. Exponential model fitted to ML and BW (y) versus age (x) relationships by sexes.

\begin{tabular}{cccccc}
\hline & Sex & $\mathrm{n}$ & Exponential model & $\mathrm{r}^{2}$ & Testing between sexes differences \\
\hline ML vs. Age & & & & & \\
& Females & 780 & $\mathrm{y}=18.604 \mathrm{e}^{0.0103 \mathrm{x}}$ & 0.74 & $\begin{array}{l}\mathrm{F}_{\text {equal slopes }}=5.35, \mathrm{P}=0.02 * \\
\mathrm{~F}_{\text {equal intercepts }}=0.75, \mathrm{P}=0.39\end{array}$ \\
& Males & 943 & $\mathrm{y}=17.406 \mathrm{e}^{0.0107 \mathrm{x}}$ & 0.66 & \\
BW vs. Age & Females & 780 & $\mathrm{y}=0.6117 \mathrm{e}^{0.0257 \mathrm{x}}$ & 0.76 & $\mathrm{~F}_{\text {equal slopes }}=2.61, \mathrm{P}=0.11$ \\
& & & & $\mathrm{~F}_{\text {equal intercepts }}=4.11, \mathrm{P}=0.04 *$ \\
& Males & 943 & $\mathrm{y}=0.5588 \mathrm{e}^{0.026 \mathrm{x}}$ & 0.71 & \\
\hline
\end{tabular}

$\mathrm{n}$ : number of specimens.

* Significant at $P<0.05$.

Growth in ML and BW in both sexes was best described by the exponential model (Fig. 4). For both relationships, significant differences were found between sexes (Table 3 ). The swordtip squid is a rather fast-growing squid. Absolute daily growth rates (DGR) in ML and BW were slow before 160 days old (Fig. 5). However, both the ML and BW increased rapidly with age and reached their maximum values at the ages of 220-240 days. The maximum ML in male and female was 4.3 $\mathrm{mm} /$ day and $2.3 \mathrm{~mm} /$ day, and the BW was $6.9 \mathrm{~g} /$ day and 4.9 g/day respectively. However, DGR for ML and BW was similar in both sexes until 200-220 days old, after which it became relatively higher for males.

Instantaneous relative growth rates $(\mathrm{G})$ of $\mathrm{ML}$ and $\mathrm{BW}$ changed similarly during our study period for both sexes, with the maximum values at the 220-240 days. The maximum $\mathrm{G}$ of ML and BW in females was less than those of males.

\section{Age at Maturity}

The sex of the specimens could be identified with the differences of arm formula between genders by eye beginning at $47 \mathrm{~mm}$ for males and $48 \mathrm{~mm}$ for females. It is an earlymaturing squid. The youngest mature female in our samples was 139 days old. More than one-half of females were maturing or mature at the age of 200-220 days (Fig. 6), and fully mature after 240 days. The youngest mature male was 102 days old. Half of the males were maturing at the age of 

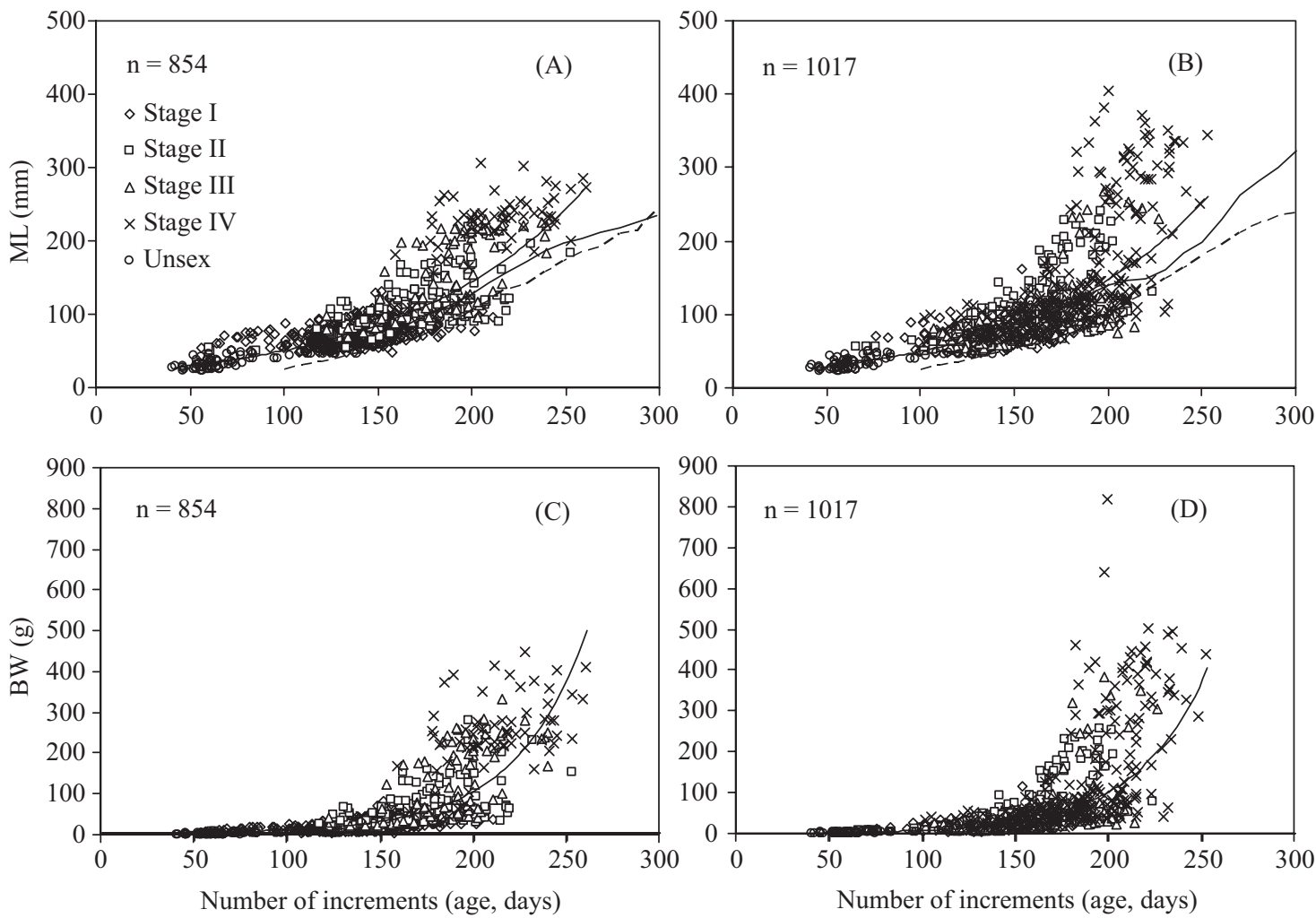

Fig. 4. Relationship between age and ML of females (A) and male (B); between age and BW of females (C) and males (D) and exponential growth curves of all combined samples of the swordtip squid of the southern East China Sea. The growth curve in the western Sea of Japan is shown in figure (A) and (B), where the thin curve indicate warm-season brood, dotted curve indicate cold-season brood, refer to Natsukari et al. [17].
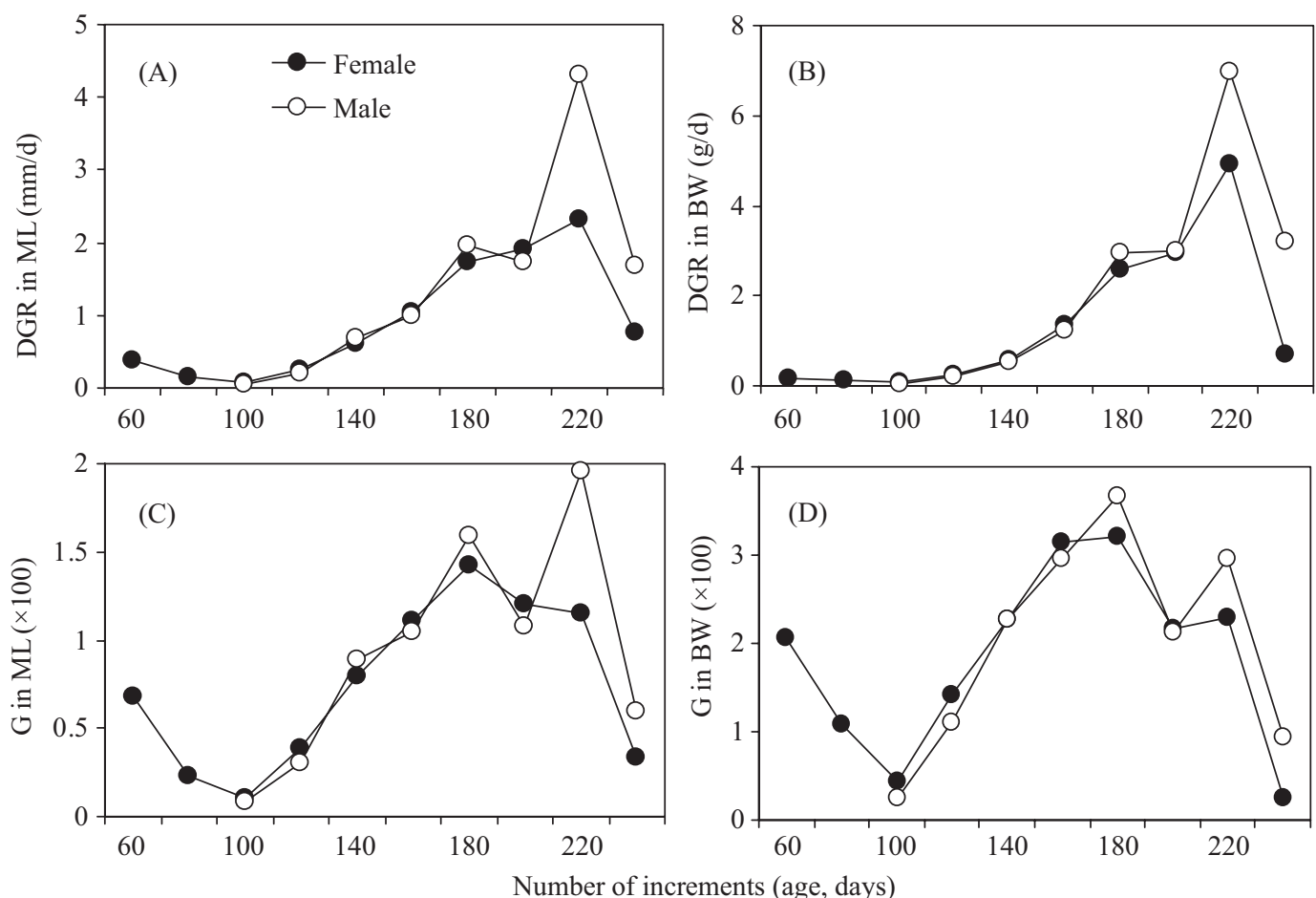

Fig. 5. Absolute DGRs of ML (A) and BW (B), and instantaneous growth rates, G, of ML (C) and BW (D) for females and males of the swordtip squid. 

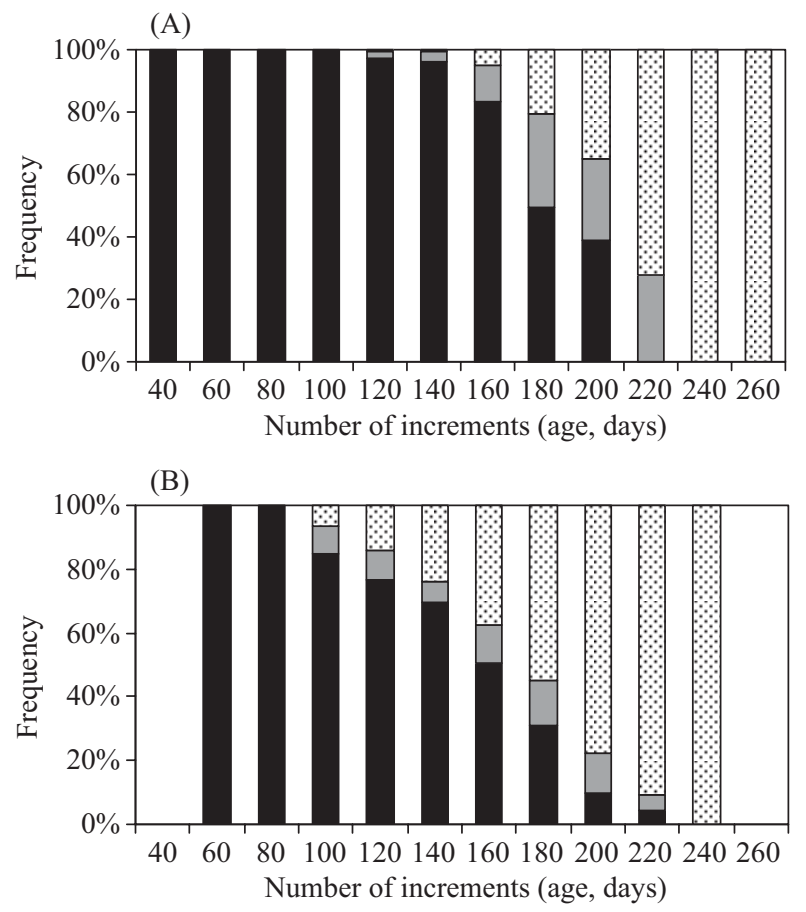

Fig. 6. Maturation in females (A) and males (B) of the swordtip squid. Black, gray and dots indicate immature, maturing and mature squid, rspectively.

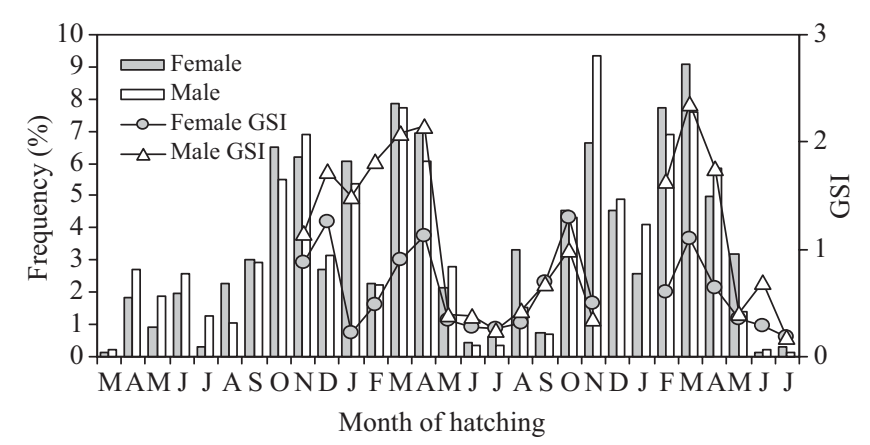

Fig. 7. Monthly hatching date frequency distribution and GSI for both sex of the swordtip squid sampled from the southern East China Sea during the period of November, 2002 to November, 2004.

180-200 days, and fully mature after 240 days. Mature females appeared about two months later in age than mature males.

\section{Hatching Time}

Figure 7 shows the frequency distribution of hatching dates for all squid and monthly GSI of both sexes. Based on backcalculated hatching dates, swordtip squid spawns throughout the year with several peaks during our study period, i.e., October-November in 2002, March-April and November in 2003, March in 2004. The correlation between hatching date frequency and the GSI during the time interval in which both data were available was positive (female: $r^{2}=0.21, P<0.05$; male: $\left.r^{2}=0.37, P<0.01\right)$. This suggests a direct relationship between the reproduction seasons and hatchings.

\section{DISCUSSION}

\section{Age and Growth}

It has already been pointed out that a lifespan of about 1 year for the swordtip squid population of the Sea of Japan (temperate waters) [17] is much longer than that of about 9 months estimated for our studied population from the southern East China Sea (subtropical waters). However, the age-ML relationship (Fig. 4) also indicated that the swordtip squid grew faster in the subtropical waters than in the temperate waters [17]. Temperature may vary with season, latitude, and water depth. Within the biokinetic range for a species (in most cephalopods), higher temperature leads to higher growth rate $[4,6]$. This explains why the growth model (age and ML or BW) of both sexes were exponential in the southern East China Sea and different from the logistical models of this species in the Sea of Japan. The differences in growth of teuthids in the habitats of different water temperatures have been also noted [14].

Statoliths of juveniles ( $<60 \mathrm{~mm}$ ML) were relatively larger ( 1.9 to $3.05 \% \mathrm{ML}$ ) than those of adults (up to $0.48 \% \mathrm{ML}$ ), owing to the strong negative allometry of statolith length versus mantle length. The growth in statolith or body between females and males in our study were significantly different, as those in the temperate waters [17].

The growth rates (DGR and G) of both sexes became noticeably different after 220 days of age, i.e., male growing faster than female. Furthermore, DGR and $G$ values of both sexes were also highest (except male $\mathrm{G}$ in $\mathrm{BW}$ ) at the age class of 220-240 days. Natsukari et al. [17] noted that the warmseason brood in the Sea of Japan grew differently between sexes after the age of 240 days. This may be one of characteristic features of the species in the southern East China Sea or in the Sea of Japan, male would grow faster than female after 220 days old.

The maximum growth rate of males $(5 \mathrm{~mm} /$ day) in our study agrees well with the statoliths analysis and tag recovery experiments of the present species in the Sea of Japan [16, 17]. The instantaneous growth rates do not continually decrease throughout the studied period. This result is different from those of other teuthids, such as Lolliguncula brevis, Dosidicus gigas, and Thysanoteuthis rhombus [9, 13, 18] but is similar to some teuthids, such as Illex coindetii and Photololigo edulis [7, 17]. Based on this result, the causes of variability in growth rates among age-classes may include both biotic (age, size, sex, etc.), abiotic (temperature, light, salinity, etc.) [4], and different microcohorts [7].

\section{Maturity and Hatching Dates}

Mature males started to appear after the age of 100-120 days while mature females appeared at the age of 160-180 days. 
Similar results were found in other Myopsina [9, 15] and Oegopsida [1, 2, 20].

Back calculation of hatching dates through statolith analysis has shown that spawning of the swordtip squid in the southern East China Sea occurs throughout the year, in conform with the results based on the monthly changes in the GSI or percentage of mature specimens [21,22]. However, a clear pattern was found in hatching dates distribution in the present study, suggesting two main spawning seasons, namely, spring season (March-April) and autumn season (October- November). We calculated $93 \%$ of mature male squids in spring were hatched in autumn of the previous year, and $98 \%$ of the mature male squids in autumn were hatched in spring of the same year. Therefore, we believe that the swordtip squid has two spawning seasons per year. This result agrees with that of our previous study [21]. Natsukari et al. [17] also reported that the swordtip squid has two spawning seasons in the Sea of Japan.

\section{ACKNOWLEDGMENTS}

We would like to express our appreciation to the people who provided their help during this study. We also extend our appreciation to Dr. Chang-tai Shih, Visiting Professor of National Taiwan Ocean University from the Canadian Museum of Nature, for his critical review and comments on the manuscript. This study was financially supported by a grant (NSC 95-2313-B-019-017) from the National Science Council of Republic of China and another grant (95AS-14.1.1-FA-F3) from the Fisheries Agency, Council of Agriculture, Taiwan, R.O.C.

\section{REFERENCES}

1. Arkhipkin, A., "Age and growth of the mesopelagic squid Ancistrocheirus lesueurii (Oegopsida: Ancistrocheiridae) from the central-east Atlantic based on statolith microstructure," Marine Biology, Vol. 129, pp. 103-111 (1997)

2. Arkhipkin, A., Jereb, P., and Ragonese, S., "Growth and maturation in two successive seasonal groups of the short-finned squid, Illex coindetii from the Strait of Sicily (central Mediterranean)," ICES Journal of Marine Science, Vol. 57, pp. 31-41 (2000).

3. Arkhipkin, A. and Mikhery, A., "Age and growth of the squid Sthenoteuthis pteropus (Oegopsida, Ommastrephidae) from the Central-East Atlantic," Journal of Experimental Marine Biology and Ecology, Vol. 163, pp. 261276 (1992).

4. Boyle, P. R., Cephalopods Life Cycles, Vol. 2, Academic Press, London, (1987).

5. FAO, FAO species catalogue, Vol. 3, Cephalopods of the world, FAO Fiseries Synopsis No. 125, pp. 86-90 (1984).

6. Forsythe, J. W., "Accounting for the effect of temperature in nature: from hypothesis to practice," Marine and Freshwater Research, Vol. 55, pp. 331-339 (2004).

7. González, A. F., Castro, B. G., and Guerra, A., "Age and growth of the short-finned squid Illex coindetii in Galician waters (NW Spain) based on statolith analysis," ICES Journal of Marine Science, Vol. 53, pp. 802-810
(1996).

8. Jackson, G. D., "Advances in defining the life histories of myopsid squid," Marine and Freshwater Research, Vol. 55, pp. 357-365 (2004).

9. Jackson, G. D., Forsythe, J. W., Hixon, R. F., and Hanlon, R. T., “Age, growth, and maturation of Lolliguncula brevis (Cephalopoda: Loliginidae) in the northwestern Gulf of Mexico with a comparison of lengthfrequency versus statolith age analysis," Canadian Journal of Fisheries and Aquatic Sciences, Vol. 54, pp. 2907-2919 (1997).

10. Liao, C. H., Lee, M. A., Lan, Y. C., and Lee, K. T., "The temporal and spatial change in position of squid fishing ground in relation to oceanic features in the northeastern waters of Taiwan," Journal of the Fisheries Society of Taiwan, Vol. 33, pp. 99-113 (2006).

11. Ling, J. and Zheng, Y., "Stock assessment of cephalopoda in East China Sea and Yellow Sea," Marine Fisheries, Vol. 22, pp. 60-62 (2000). (in Chinese with English abstract)

12. Macy, W. K., "Development and application of an objective method for classifying long-finned squid, Loligo pealei, into sexual maturity stages," Fishery Bulletin, Vol. 80, pp. 449-459 (1982).

13. Markaida, U., Quiñónez-Velázquez, C., and Sosa-Nishizaki, O., “Age, growth and maturation of jumbo squid Dosidicus gigas (Cephalopoda: Ommastrephidae) from the Gulf of California, Mexico," Fisheries Research, Vol. 66, pp. 31-47 (2004).

14. Miyahara, K., Ota, T., Goto, T., and Gorie, S., "Age, growth and hatching season of the diamond squid Thysanoteuthis rhombus estimated from statolith analysis and catch data in the western Sea of Japan," Fisheries Research, Vol. 80, pp. 211-220 (2006).

15. Moreno, A., Azevedo, M., Pereira, J., and Pierce, G. J., "Growth strategies in the squid Loligo vulgaris from Portuguese waters," Marine Biology Research, Vol. 3, pp. 49-59 (2007).

16. Moriwaki, S., Yamada, H., Takeda, R., Kawano, M., and Natsukari, Y., Growth and birth date of Loligo edulis in the coastal waters of the western Japan Sea, Rep. Cooperative Investigation of "Shiro-ika", Loligo edulis, inhabited in the western Japan Sea, No. 2, pp. 19-27 (1986). (in Japanese with English abstract)

17. Natsukari, Y., Nakanose, T., and Oda, K., "Age and growth of loliginid squid Photololigo edulis (Hoyle, 1885)," Journal of Experimental Marine Biology and Ecology, Vol. 116, pp. 177-190 (1988).

18. Nigmatullin, C. M., Arkhipkin, A. I., and Sabirov, R. M., "Age, growth and reproductive biology of diamond-shaped squid Thysanoteuthis rhombus (Oegopsida: Thysanoteuthidsae)," Marine Ecology Progress Series, Vol. 124, pp. 73-87 (1995).

19. Pierce, G. J., Boyle, P. R., Hastie, L. C., and Key, L. N., "The life history of Loligo forbesi (Cephalopoda: Loliginidae) in Scottish waters," Fisheries Research, Vol. 21, pp. 17-41 (1994).

20. Uozumi, Y. and Ohara, H., "Age and growth of Nototodarus sloanii (Cephalopoda: Oegopsida) based on daily increment counts in statoliths," Nippon Suisan Gakkaishi, Vol. 59, pp. 1469-1477 (1993).

21. Wang, K. Y., Liao, C. H., and Lee, K. T., "Population and maturation dynamics of the swordtip squid (Photololigo edulis) in the southern East China Sea," Fisheries Research, Vol. 90, pp. 178-186 (2008).

22. Wang, Y., "Fishery biological characteristics of swordtip squid Loligo edulis in the southern part of the East China Sea," Marine Fisheries, Vol. 4, pp. 169-172 (2002). (in Chinese with English abstract)

23. Yamada, U., Tagawa, M., Kishida, S., and Honjo, K., Fishes of the East China Sea and the Yellow Sea, Seikai Reg. Fish. Res. Lab, Nagasaki. (1986). (in Japanese)

24. Zheng, Y., Ling, J., Yan, L., Zhou, J., and Shen, J., "Cephalopod resources and rational utilization in East China Sea," Journal of the Fishery Sciences of China, Vol. 6, pp. 52-56 (1999). (in Chinese with English abstract) 